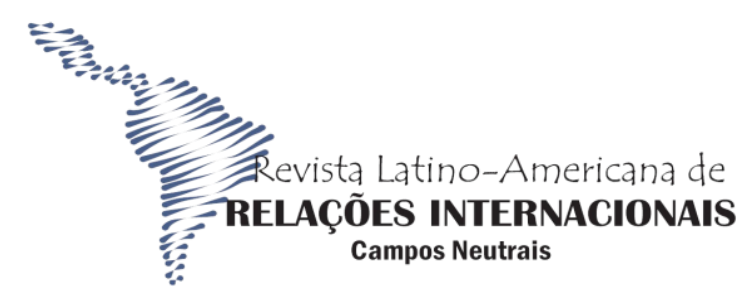

\title{
O Coronelismo na colônia: a República Velha no Noroeste do RS
}

Colonelism in the colony: the Old Republic in the Northwest of RS

Dejalma Cremonese

Hemerson Pase

Ana Paula Dupuy Patella

Resumo: Este trabalho tem como objetivo discutir o coronelismo, no sistema político brasileiro, como mecanismo privilegiado para o acesso e permanencia no poder. O problema principal é que tipo de relação se estabeleceu entre os líderes partidários e os colonos recém-chegados ao Noroeste do RS? A hipótese afirma que a relação era coronelista, marcada pelo controle clientelista e autoritário. A metodologia utilizada é qualitativa, apoiada em referencias bibliograficas, pesquisa secundária a partir de registros históricos e de entrevistas sobre o Rio Grande do Sul e especialmente o caso do município de Ijuí no período entre 1890-1930.

Palavras-chave: Cultura política, clientelismo, mandonismo

\begin{abstract}
This work aims to discuss coronelism, in the Brazilian political system, as a privileged mechanism for access and permanence in power. The main problem is what kind of relationship was established between partisan leaders and newly arrived colonists in the Northwest of RS? The hypothesis affirms that the relation was coronelista, marked by the control clientelista and authoritarian. The methodology used is qualitative, supported by bibliographical references, secondary research based on historical records and interviews about Rio Grande do Sul and especially the case of the municipality of Ijuí in the period between 1890-1930.
\end{abstract}

Keywords: Political culture, clientelism, mandonismo 


\section{Introdução}

A política da República Velha é caracterizada pelo coronelismo, cuja marca é uma complexa rede de relações que integrava através de compromissos recíprocos as ações do líder político local (coronel) ao presidente da República passando pelo presidente da província e pelos parlamentares estaduais e federais. Além de relações de lealdade produzidas a partir de moedas do clientelismo, patrimonialismo e paternalismo, o coronelismo possibilitava aos mandões locais a manutenção e controle político através de práticas autoritárias, a capangagem.

No Rio Grande do Sul o coronel originalmente era chamado de caudilho, caracterizadoe pela ruralidade, cuja atividade econômica principal era pecuária e a relação como a fronteira. Estas características influenciam a ideologia urbana do positivismo castilhista-borgista, proporcionando a emergência de coronéis urbanos, ligados ao setor comercial, como é o caso de Antonio Soares de Barros, o Cel. Dico, objeto deste estudo.

Este trabalho tem como objetivo discutir o coronelismo, no sistema político brasileiro, como mecanismo privilegiado para se ter acesso e permanecer no poder. A metodologia utilizada é qualitativa, apoiada em referencias bibliograficas e na história oral sobre o Rio Grande do Sul e especialmente o caso do município de Ijuí no período entre 1890-1930.

O texto está dividido em quatro seções, cuja primeira apresenta o Rio Grande do Sul na República Velha e a polarização política entre os partidos Republicano e Liberal. A segunda seção apresenta um debate sobre as principais características do coronelismo no Brasil a partir da literatura clássica. Na terceira seção discute-se a experiência política de Ijuí, noroeste do Estado do Rio Grande do Sul, tendo como principais expoentes os coronéis Augusto Pestana e Antonio Soares de Barros. Na quarta e última seção discutem-se as peculiaridades políticas e autoritárias dos coronéis do Noroeste do Rio Grande do Sul.

\section{A política do Rio Grande do Sul na República Velha}

Nos primeiros anos da República Velha, a administração do estado do Rio Grande do Sul passou por uma instabilidade política bastante acentuada: de 1889 até o início de 1893 , o governo do estado passaria pelas mãos de dezoito presidentes, evidenciando o caos político (CAVALARI, 2001). Após a vitória dos republicanos (pica-paus) na Revolução Federalista (189395), o cenário político rio-grandense entra num período de (pseudo) calmaria até os ânimos novamente se alterarem e chegarem às vias de fato com a revolução de 1923. 
Os dois principais partidos políticos do Rio Grande do Sul na República Velha provêm da polarização entre republicanos e liberais (TRINDADE, 1979; e TRINDADE e NOLL, 1991; PICCOLO,1979). Os republicanos (de inspiração positivista, tinham como principal liderança Júlio de Castilhos) fundaram o Partido Republicano Rio-Grandense (PRR) em 1882, cujas principais lideranças políticas eram Pinheiro Machado, Júlio de Castilhos, Borges de Medeiros e Ramiro Barcellos todos com forte influência das ideias de Augusto Comte (PINTO, 2003; BAQUERO e PRÁ, 1995; FREITAS, 2000). Os conservadores liberais, liderados por Gaspar da Silveira Martins, fundaram o Partido Federalista (PF) em 1893; mais tarde, a Aliança Libertadora em 1924 e o Partido Libertador em 1928. Fazia parte desse partido a elite tradicional do Rio Grande do Sul. O Partido Liberal Federalista era mais forte na região da fronteira, onde os fazendeiros e os comerciantes se mostravam indignados com a rígida política anticontrabando dos republicanos e a falta de incentivos à pecuária.

O Partido Liberal foi constituído no Império. Quando foi proclamada a República, o antigo Partido Liberal passou a ser chamado de Partido Federalista. Sua área de atuação deu-se na zona da fronteira sul e campanha, onde predominava o latifúndio, com grandes estâncias de criação de gado (charqueadas), cujos interesses defendia. Como diz Félix (1987): “É o reduto mais identificado, no Império, com o Partido Liberal e, mais tarde, na República, com o Partido Federalista” (p. 46).

O PRR era formado por pecuaristas e teve como aliadas as classes médias urbanas e suas políticas de inclusão operária. As características principais da administração do PRR foram a prática do coronelismo na política, o voto a descoberto, a união Estado-Exército e Estado autoritário. Depois, porém, estando o PRR no poder, desenvolveu um projeto político não oligárquico, na medida em que procurou se credenciar como defensor dos interesses de vários segmentos da sociedade e não apenas da elite estancieira, como ocorria na fase de predomínio do Partido Liberal do Império (PINTO, 1986).

O PRR governou o Rio Grande do Sul com "mão de ferro", abaixo de acusações de fraude, por 35 anos ininterruptos. Júlio de Castilhos, eleito presidente da Província do Rio Grande do Sul em julho de 1891, governou sob pesada oposição dos federalistas, muitos deles nostálgicos do Império. Castilhos inovou em matéria constitucional, priorizando a concentração do poder no Executivo. Contrariando a orientação da tripartição e equilíbrio dos poderes públicos da Constituição Federal (1891), a Constituição gaúcha de 14 de julho de 1891 estabelecia, como norma essencial, a predominância do executivo sobre os outros 


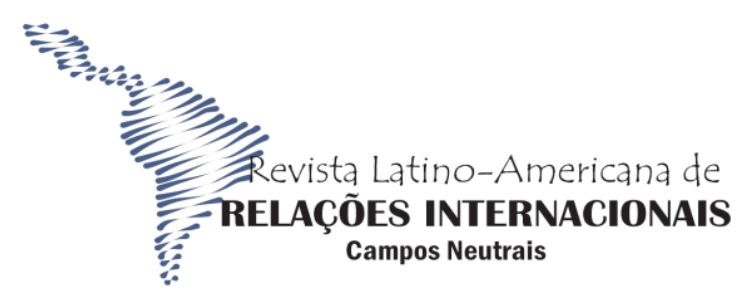

FURG

poderes, assim concentrando o poder de legislar, de maneira praticamente exclusiva, nas mãos do presidente do Estado (VÉLEZ, 1982).

A estrutura autocrática de predomínio do Executivo já era uma realidade em nível nacional no autoritarismo dos republicanos e na retórica dos líderes propagandistas nos governos de inspiração positivista na República Velha, como os governos de Deodoro da Fonseca (1889-1891), de Floriano Peixoto (1891-1894), de Prudente de Moraes (1894-1898) e de Campos Sales (1898-1902).

A República Velha (1889-1930) caracterizou-se como conservadora, oligárquica e regionalista. Em nível local os republicanos se utilizaram de líderes políticos denominados de coronéis, que prestavam apoio e fidelidade aos quadros políticos do estado e do país (governadores e presidentes da República), para garantir resultados que agradassem ao sistema dominante. Favores pessoais e empreguismo de um lado, e repressão de outro, caracterizaram fortemente as relações políticas nesse período de laizzez-faire repressivo (NUNES, 2003).

\section{$2 \mathrm{O}$ coronelismo}

O debate sobre o coronelismo foi tratado especificamente por Victor Nunes Leal, na obra Coronelismo, enxada e voto, publicada em 1948. Na concepção de Leal, o coronelismo é visto como um sistema político, uma complexa rede de relações que vai desde o coronel até o presidente da República, envolvendo compromissos recíprocos. O autor tratou da relação entre o poder local e o poder nacional na qual o coronel era elemento essencial.

O coronelismo surge dentro de um contexto histórico específico, inserido na conjuntura política e econômica do Brasil no período da República Velha (1889-1930), quando se estabelece a federação, implantado em substituição ao centralismo imperial. A partir desse evento, criou-se um ator político com amplos poderes: o presidente de Estado.

\begin{tabular}{|l|l|l|l|l|} 
ISSN 2596-1314 \\
CAMPOS NEUTRAIS & Rio Grande & v. 3, n. 2 & p. 72-94 & Maio-Ago 2021 \\
REVISTA LATINO-AMERICANA DE RELAÇÕES INTERNACIONAIS & & &
\end{tabular}


O coronelismo foi um sistema político nacional baseado na "troca de favores" entre o governo central e os detentores do poder local. As relações entre o poder local (coronéis) e o governo podem ser descritas como um caminho de duas vias, ou seja, cada um dos atores políticos necessitava do outro para sobreviver:

O governo estadual garantia, para baixo, o poder do coronel sobre seus dependentes e seus rivais, sobretudo cedendo-lhe o controle dos cargos públicos, desde o delegado de polícia até a professora primária. O coronel hipoteca seu apoio ao governo, sobretudo na forma de votos. Para cima, os governadores dão seu apoio ao presidente da República em troca do reconhecimento deste seu domínio no Estado. O coronelismo é a fase de processo mais longo de relacionamento entre os fazendeiros e o governo (CARVALHO, 1997).

Leal seguiu a definição de Basílio de Magalhães para explicar a origem do conceito de coronelismo no Brasil:

O tratamento de 'coronel' começou desde logo a ser dado pelos sertanejos a todo e qualquer chefe político, a todo e qualquer potentado, até hoje recebem popularmente o tratamento de 'coronéis' os que têm em mãos o bastão de comando da política edilícia ou os chefes de partidos de maior influência na comuna, isto é, os mandões dos corrilhos de campanário (LEAL, 1975, p. 20-21).

Os trabalhadores rurais, desprovidos de qualquer estrutura que lhes possibilitasse mudança de vida, eram dependentes do coronel. Segundo Leal

[...] completamente analfabeto, ou quase, sem assistência médica, não lendo jornais, nem revistas, nas quais se limita a ver as figuras, o trabalhador rural, a não ser em casos esporádicos, tem o patrão na conta de benfeitor. E é dele, na verdade, que recebe os únicos favores que sua obscura existência conhece (LEAL, 1975, p. 25).

A troca de favores era a essência do compromisso coronelista, que consistia em apoiar os candidatos do oficialismo nas eleições estaduais e federais: “[...] enquanto que, da parte da situação estadual, vinha carta branca ao chefe local governista (de preferência o líder da facção local majoritária) em todos os assuntos relativos ao município, inclusive na nomeação de funcionários estaduais do lugar" (LEAL, 1975, p. 50).

O coronelismo é a forma como se solucionam as relações de poder no sistema político brasileiro durante a República Velha, cujo principal objetivo é definir o acesso e a permanência nas posições de mando do governo, o que garante protagonismo na definição dos rumos do Estado. Essa solução é viabilizada através de algumas características específicas, tais como o mandonismo e o filhotismo, o falseamento do voto, o voto de cabresto e a capangagem, e outras mais comuns que perpassam a cultura política brasileira e permanecem até a atualidade como o clientelismo, o patrimonialismo e o paternalismo.

O clientelismo é uma relação de poder verticalizada, cuja característica essencial é a troca de favores desde o nível micro, na relação entre o líder local e os cidadãos comuns, 


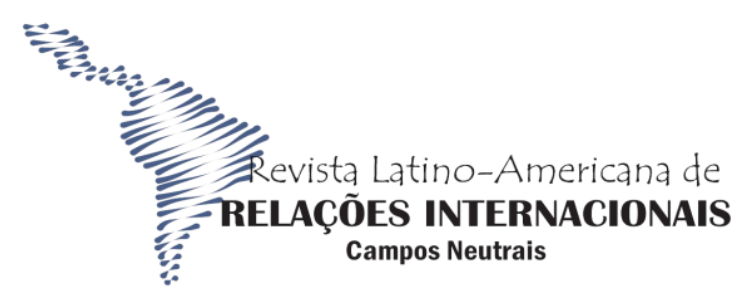

FURG

passando pela relação entre aquele e o líder regional e/ou estadual e, por fim, chegando a influenciar na correlação de forças nacionais. Na Primeira República a capacidade de eleição de um candidato a cargo público estava diretamente relacionada à sua capacidade de prestar favores (nomeação para cargos públicos, liberação de verbas, concessão de obras, títulos de posse de terras, e outros) para os seus correligionários locais e/ou regionais que, por sua vez, eram líderes, coronéis e/ou mandões, que garantiam seu poderio trocando favores (proteção, permissão de trabalhar como agregado, trabalho assalariado ou serviços públicos) por lealdade, materializada por trabalho na grande propriedade, por serviços militares e, principalmente, por votos, cujo destino obedece à sua ordem.

O coronelismo acrescenta ao clientelismo a característica autoritária e violenta, manifestada pelo papel exercido pelos capangas, grupos armados que servem ao mandão, atuando na 'limpeza moral', executando os 'julgamentos' proferidos por aquele.

Para Love (1975), o coronelismo gaúcho, diferentemente do restante do país, está ligado essencialmente à pecuária (grandes propriedades para criação de gado), em que os grandes estancieiros detêm o controle do poder local, subordinados politicamente aos ditames dos chefes políticos estaduais, os "de cima". Love chama o coronel, dono do poder local, de "coronel burocrata". O coronel burocrata era responsável pelo aliciamento dos eleitores com o objetivo de obter os votos necessários para o seu partido, o republicano, que era, evidentemente, um dos maiores partidos do Rio Grande do Sul. O objetivo era manter o status quo e impedir que os eleitores opositores votassem, o que era uma forma de "abortar" qualquer tentativa de fortalecimento da oposição. Quando necessário, a fraude, a violência e a intimidação eram a prática "comum" para atingir as quotas de votos, utilizando, muitas vezes, a força de homens armados, pessoalmente leais, chamados popularmente de "capangas", ou "gente do coronel", encarregados de fazer o "serviço sujo".

Para Carvalho (1997), os diferentes estudos sobre o coronelismo possibilitam um entendimento abrangente do termo. Pode-se encontrá-lo em diferentes segmentos sociais. Para alguns teóricos, o conceito de coronelismo está ligado ao dono do latifúndio, outros o

\begin{tabular}{|l|l|l|l|l|}
\multicolumn{1}{|c|}{ ISSN 2596-1314 } \\
CAMPOS NEUTRAIS & Rio Grande & v. 3, n. 2 & p. 72-94 & Maio-Ago 2021 \\
REVISTA LATINO-AMERICANA DE RELAÇÕES INTERNACIONAIS & &
\end{tabular}


relacionam com os grandes estancieiros (criadores de gado), mas existiu também o coronel médico, o coronel comerciante e até o coronel padre

O coronel era o líder local, estando a serviço do partido oficial em seu Estado. Sobre o processo eleitoral, era função do coronel apresentar o número de votos consignados - e impedir a oposição de votar. O coronel quase sempre aliciava os eleitores de seu distrito mediante favores pessoais, conseguindo-lhes emprego, arranjando-lhes empréstimos ou simplificando processos burocráticos. Diz Love que, acaso o aliciamento não desse resultado, a violência e a fraude eram utilizadas para atingir o número desejado de votos,

[...] usando a força de homens armados e pessoalmente leais. Em troca dos votos apresentados pelo seu município (ou grupos de municípios), ao coronel era dado o controle do patronato local, que compreendia certos cargos no 'funcionamento' público, tais como o de professor (LOVE, 1975, p. 126).

O coronelismo está ligado diretamente a chefes políticos que exercem poder sobre um determinado grupo que os legitima e apoia.

Entendemos por coronelismo o poder exercido por chefes políticos sobre certo
número de pessoas que deles dependem. Tal situação visa objetivos eleitorais que
permitam aos coronéis a imposição de nomes para cargos que eles indicam. Têm
sua autoridade reconhecida pelo consenso do grupo social de base local, distrital
ou municipal e, algumas vezes, regional, geralmente devido ao seu poder
econômico de grandes estancieiros ou grandes proprietários (FELIX, 1987, p. 16).

No aspecto das relações sociais e políticas, embora assentadas na pecuária e no latifúndio, o Rio Grande do Sul parece-se, porém, com outras regiões do Brasil. O argumento de Félix justifica esta ideia:

[...] a propriedade privada, responsável pelo universo da cultura pastoril, no seu sentido mais amplo. Unidade montada sob a forma de latifúndio, idêntico, em suas linhas gerais, ao resto do Brasil: grande propriedade; patriarcalismo; senhores, agregados e escravos formando as diferentes camadas sociais (FELIX, 1987, p. 27).

A característica principal do estancieiro era o autoritarismo com que tratava seus subalternos (peões, agregados e escravos). Ao mesmo tempo, o estancieiro era o chefe no seu grupo social, mas era o coronel que dominava a política do distrito e do município. O estancieiro foi também chamado de caudilho, pois exercia a dominação local, além de garantir meios econômicos especiais junto aos líderes políticos. O caudilho era proprietário de terra e exercia relações de compadrio (fidelidade) com pessoas influentes, a fim de obter proveitos pessoais.

\section{0 coronelismo na colônia: a experiência de Ijuí}




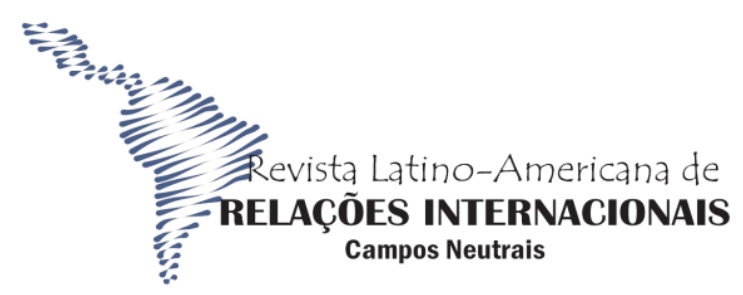

Esta seção discute duas personalidades centrais do cenário da política regional com caracterísiticas coronelísticas, o Coronel Augusto Pestana e Antonio Soares de Barros, o Coronel Dico.

Augusto Pestana teve a incumbência de reestruturar a colônia de Ijuí, formada pelo território do, mais tarde, $5^{\circ}$ Distrito de Cruz Alta e fundada oficialmente em 30 de maio de 1890, pelo engenheiro José Manoel da Siqueira Couto. Recebeu, em 19 de outubro do mesmo ano, a primeira leva de imigrantes europeus, encaminhados pelo Serviço de Terras e Colonização. É necessário considerar que muitos dos primeiros imigrantes não eram agricultores, o que dificultava a sua adaptação: “[...] em grande parte dos poloneses, os teutorussos, os austríacos, os alemães e os suecos eram industriários que não possuíam a mínima idéia das lides agrícolas" (FISCHER, 1968, p.16). Outra dificuldade inicial para a colônia emergente foi a Revolução Federalista de 1893 e a catástrofe que se abateu sobre a economia do Estado.

O município de Cruz Alta foi um dos principais focos da revolução e Ijuí (5 Distrito) sofreu prejuízos inestimáveis. Além do despovoamento começara a afetar a colônia recém-criada “[...] um novo flagelo, pior que todos os outros: a discórdia. Discórdia aberta, provocada em parte pela mais triste situação econômica que criava nervosismo e desarmonia em toda a colônia" (LAZZAROTTO, 1986, p. 17).

As lideranças políticas do município de Ijuí, mesmo sendo republicanas, procuraram não se envolver diretamente na Revolução, mesmo assim pendengas e rixas entre chimangos e maragatos foram constantes. Estudos demonstram que, por volta de 1909, essas divergências se acentuaram, fazendo com que Augusto Pestana, líder político da colônia, convocasse os lados envolvidos para uma reunião, que se realizou à sombra de duas frondosas figueiras que existiam no alto da Coxilha Sudeste da Vila Ijuí. Nesta ocasião, Pestana conclamou a todos para a união, para o desenvolvimento e o progresso da região. Em 1917, o intendente Antônio Soares de Barros, recordando da reunião realizada no alto

\begin{tabular}{|c|c|c|c|} 
ISSN 2596-1314 \\
CAMPOS NEUTRAIS & Rio Grande & v. 3, n. 2 & p. 72-94 \\
REVISTA LATINO-AMERICANA DE RELAÇÕES INTERNACIONAIS & Maio-Ago 2021 & & \\
\hline
\end{tabular}


da coxilha, batizou o lugar com o nome de "Alto da União" (LAZZAROTTO, 1986, p. 1617).

Mais tarde, no ano de 1923, os dois grupos oponentes (Chimangos e Maragatos) voltaram aos combates nos campos do Rio Grande do Sul. O município de Ijuí, indiretamente, acabou sendo afetado pela Revolução Federalista.

A Revolução Federalista dividiu os gaúchos, e isso não fora diferente na colônia de Ijuí: uma parte dos moradores declarou-se abertamente partidária dos federalistas, enquanto outra permaneceu fiel ao governo, antagonismo que agravou ainda mais a crise e a miséria. Com isso, atos de violência não tardaram a chegar: "E o pior de tudo era que o banditismo começou a fazer sentir aberta e desavergonhadamente, já que uma região coberta de tanto mato oferecia ótimos esconderijos a toda espécie de malfeitores. Este estado de coisas sobreviveu à revolução por alguns anos" (LAZZAROTTO, 1986, p. 17).

Foi então com o objetivo de "salvar" a colônia do colapso iminente que o governo nomeou Augusto Pestana para dirigi-la. Empossado neste cargo a $1^{\circ}$ de janeiro de 1899, no dia 8 de janeiro chegou a Ijuí para administrar e comandar a colônia por longos treze anos de forma consecutiva. Aos poucos, Pestana conseguiu reverter a situação de Ijuí, que se encontrava em situação precária. Fischer comenta que Pestana obteve, em um tempo relativamente curto, um substancial sucesso graças à utilização da força e da imposição da ordem. Sujeitos indesejáveis não duravam muito tempo nessas plagas:

“[...] o chefe era implacável com vagabundos, beberrões, brigões e agitadores. Quando tinham concessão de terras, pagava até indenizações ou anulava contratos de compra para desta maneira livrar a colônia de elementos irresponsáveis. A luta de vida e morte empreendida por Augusto Pestana para "pacificar" os ânimos mais exaltados fazia com que o próprio coronel andasse fortemente armado, pois na época não tirava nunca a sua faca de prata da cava do colete, nem o revólver 38 da cintura ((FISCHER, 1968, p. 19 - 20).

A autocracia foi a característica principal adotada por Augusto Pestana para administrar a colônia. A participação popular ficou bastante limitada. Práticas de clientelismo e de paternalismo político não tardaram a acontecer.

O chefe cuidava de tudo e velava por todos, dirigia a construção de estradas e pontes, organizava os transportes e ajudava o artesanato e a pequena indústria. Como um bom pai cuida de seus filhos, assim Augusto Pestana cuidava de 'seus' colonos ((FISCHER, 1968, p. 21).

Depois de treze anos à frente da liderança política de Ijuí, Augusto Pestana vai gradativamente deixando o poder, no entanto a sua influência política permanecerá com a indicação de seu amigo Antônio Soares de Barros para assumir a intendência do município. 


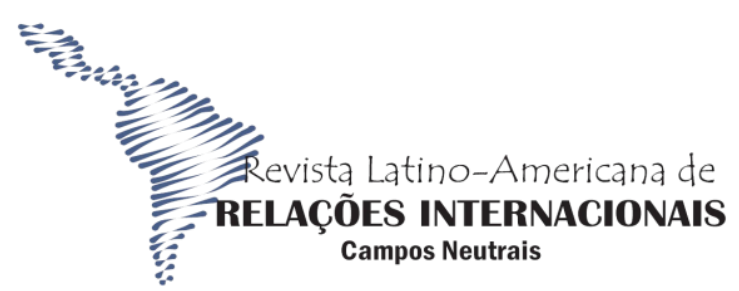

FURG

Logo após deixar a intendência do município, Augusto Pestana foi eleito Deputado Federal pelo Rio Grande do Sul, como representante do Partido Republicano Rio-Grandense (PRR), em 30 de janeiro de 1915, reelegendo-se ainda por mais duas legislaturas consecutivas.

Cabe dizer, no entanto, que a forma autocrática de governo estava ainda na fase inicial em Ijuí. Com a ausência do Coronel Pestana, assume o Coronel Antônio Soares de Barros (Cel. Dico), também republicano, que permanecerá no poder por mais de duas décadas.

Como vimos, para manter-se no poder, o governo estadual não podia prescindir da participação e do apoio de lideranças políticas locais. Os coronéis agiam com fidelidade ao chefe do Estado na sustentação de seu governo. Muitas vezes a violência foi a prática corriqueira para manter a "máquina" burocrática estatal funcionando. No Planalto Médio do Rio Grande do Sul, alguns chefes locais merecem destaque, como José Gabriel da Silva Lima, Firmino de Paula e Firmino de Paula Filho (Cruz Alta), Victor Dumoncel Filho (Santa Bárbara), Pinheiro Machado (São Luiz Gonzaga), Serafim de Moura Reis, Evaristo Teixeira do Amaral, Júlio Pereira dos Santos, Josimo Eleutério dos Santos e Ubaldino Machado (Palmeira das Missões), Ramão Luciano de Souza, o "Coronel Bicaco" (Santo Augusto) e, em Ijuí, Antônio Soares de Barros.

Depois de se estabelecer em Ijuí, inicia-se uma longa trajetória em sua vida, na economia e na política administrativa do município. Em 1910 aceitou ser correspondente do Banco Nacional do Comércio. Foi amigo próximo do então diretor Augusto Pestana. Em 11 de julho de 1912 ocupou o cargo de intendente provisório da Colônia de Ijuí, ficando até 30 de dezembro do mesmo ano. E é dessa época a sua eleição para o Conselho Municipal de Cruz Alta (Câmara de Vereadores). Quando já criado o município de Ijuí, em 1912, o Dr. Pestana afastou-se da administração municipal, vindo então o Cel. Dico, a ser eleito intendente do município. Era, concomitantemente, chefe político e dirigindo o Partido Republicano Rio-Grandense municipal.

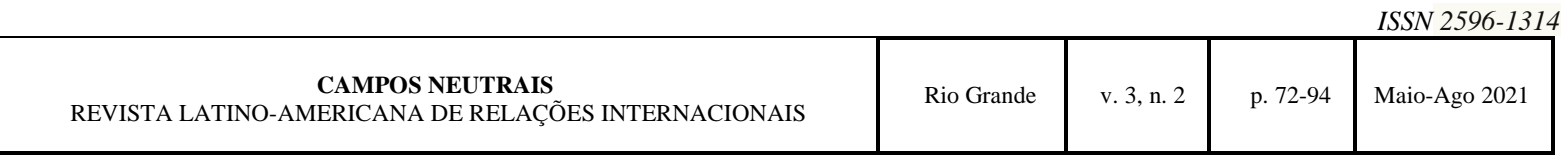


O Coronel controlava a vida de todos os cidadãos do município, cuja tarefa era responsabilidade de um grupo de "capangas", que estavam a seu serviço para fazer a "limpeza da cidade". "Para o domínio absoluto no município, o Coronel tinha uma força para-militar de no mínimo 20 capangas, podendo em caso de necessidade ter 50 ou até 200 ”. A origem étnica dos capangas era exclusivamente luso-brasileira (BARBIAN, 1986, p. 14).

Tais atos eram tolerados e discretamente aceitos entre a população. Muitos relatos orais fazem menção de que "aqui não ficava ou durava mau elemento" e, por isso, "nunca houve problemas maiores de roubo ou violência", "aqui o povo era trabalhador e ordeiro, elemento ruim é que não ficava". Se, porventura, ocorresse algum tipo de crime (roubo, atentado, rixa ou vadiagem), o "mau elemento" era, conforme o grau do delito, punido com uma surra, trabalhos forçados ou até mesmo com a pena de morte. $\mathrm{O}$ chefe dos capangas era chamado de Major Luiz Amaro, tendo cometido muitos crimes sob o comando do Cel. Dico. A impunidade era constante naqueles tempos: ninguém denunciava, ninguém sabia de nada, o silêncio era a tônica da época (LAZZAROTTO, 1995).

Antônio Soares de Barros tinha ligações estreitas com o Cel. Firmino de Paula, de Cruz Alta com quem informações e confidências eram trocadas sobre os rumos políticos dos referidos municípios e dos seus adversários políticos, mas era com os supostos "criminosos" que o "intercâmbio" funcionava: os que cometiam algum crime em Cruz Alta eram enviados para Ijuí para serem assassinados. Da mesma forma, os criminosos de Ijuí eram enviados para Cruz Alta para o mesmo fim. Segundo Barbian: “[...] como a região era toda dominada por coronéis, havia troca de favores para a execução dos chamados serviços sujos, pois o que ele não queria fazer o outro de Cruz Alta mandava executar, mandava liquidar" (BARBIAN, 1986, p.14).

O Cel. Dico tinha um modo peculiar de punir os criminosos:

[...] quanto à ladroeira, ele e o capitão Martins, era uma vez e nunca mais, sumia daqui, botavam lá na praça arrancar guanxumas, arrancar toco, eu vi um que tinha roubado um cavalo, na Linha 6 Oeste, vi um soldado com a espada e ele com as mãos cheias de sangue arrancando guanxumas, o homem chorava e gritava de dor e se não arrancava o pau pegava [...] aquele ia embora e nunca mais roubava (BARBIAN, 1986, p. 20).

Segundo fontes orais colhidas pelo Padre Pio Buzanello, disponíveis no Museu Antropológico Diretor Pestana (MADP), o Coronel dispensava os magistrados designados para trabalhar no município: “Em Ijuí não paravam fiscais nem magistrados, pois o próprio coronel os dispensava, orientando pessoalmente seus munícipes sobre questões legais e 


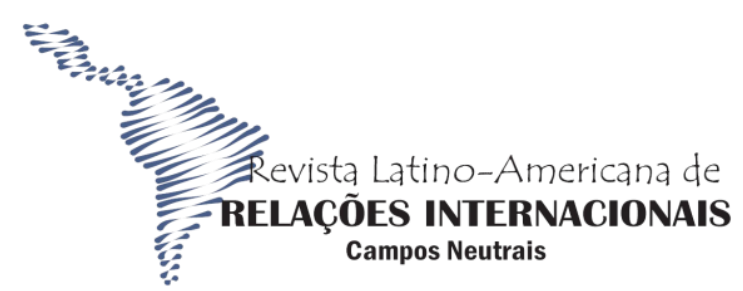

FURG

resolvendo pendengas judiciais do mesmo modo" (MADP, s/d) Isso é exemplo evidente da centralização política que impunha aos ijuienses.

\section{Coronel republicano e autoritário}

Todos os municípios do Rio Grande do Sul, na época, seguiam à risca os ditames da política republicana positivista. Em Ijuí não fora diferente. O Cel. Augusto Pestana foi o precursor dessa ideologia política a que Antônio Soares de Barros deu continuidade. Diz Avancini (p. 15): “[...] a posição do Cel. Dico era sempre a de Borges de Medeiros, mas nem por isso deixava de ser previamente consultado".

Uma característica da política da época era a longa duração dos mandatos dos dirigentes, como é o caso de Borges de Medeiros, que governou o Rio Grande do Sul durante 30 anos, de janeiro de 1898 até janeiro de 1928. Com o Cel. Dico não foi diferente: exerceu influência e poder na comunidade desde que se instalou na colônia, em 1890. Em 1912, ano em que Ijuí se emancipou, o Cel. Dico assumiu a direção política do município até 1925 , permaneceu três anos afastado, e voltou à chefia da prefeitura em 1928 e ao controle político, onde permaneceu até 1938.

Avancini descreve o período em que o Cel. Dico governou o município: "O Cel. Soares de Barros governou consecutivamente entre 1912-1925, só teve interrompido um período intendencial (1925-1927) em virtude de cláusula do Pacto de Pedras Altas, que exigia a reformulação da Constituição rio-grandense quanto à reelegibilidade dos cargos executivos". Terminado o período de Intendência, o Cel. Dico volta ao poder (AVANCINI, $\mathrm{s} / \mathrm{d}, 16-17)$.

Durante o longo período em que governou o município, o Cel. Dico jamais sentiu-se ameaçado por grupos políticos contrários à sua forma de administrar. Como nos diz Amaral (2003, p, 63), “[...] pode-se constatar que não ocorre a emergência de um grupo, ou uma pessoa que pudesse colocar em risco o poder do Cel. Dico, em âmbito local. Em relação a integrantes ligados a partidos políticos de oposição ao PRR, não foi possível detectar nenhum".

\begin{tabular}{|c|c|c|c|c|}
\multicolumn{1}{|c|}{ ISSN 2596-1314 } \\
\begin{tabular}{|l|c|c|} 
CAMPOS NEUTRAIS \\
REVISTA LATINO-AMERICANA DE RELAÇÕES INTERNACIONAIS
\end{tabular} & Rio Grande & v. 3, n. 2 & p. 72-94 & Maio-Ago 2021 \\
\hline
\end{tabular}


A impressão era de uma total convergência política, isto é, apresentada como uma comunidade sem conflitos, ordeira, pacifista e trabalhadora. A política era para os "entendidos". As decisões políticas deveriam ser deixadas ao grande líder, que as resolvia em nome de todos. Como diz Avancini:

De fato o município se caracterizou pela ausência de envolvimento nas questões políticas e revoluções do Estado gaúcho durante a República Velha Gaúcha. Pacifismo? Não. Na verdade o colono imigrante, população recente no Estado, não se identificava com as lutas partidárias de maragatos e chimangos que eram lutas entre frações de elite (AVANCINI, s/d, p. 47).

A preocupação do imigrante fosse a conquista e a posse da terra no Rio Grande do Sul, razão principal da sua vinda da Europa.

O coronelismo brasileiro esteve mais ligado à estrutura agrária, enquanto que o coronelismo gaúcho esteve mais ligado à pecuária (FÉLIX, 1987, p. 11). Em Ijuí, diferentemente da realidade brasileira e gaúcha, o coronelismo esteve ligado ao poder econômico comercial como demonstra o exemplo do Cel. Dico, constituindo o chamado “coronel burocrata" (LOVE, 1975).

Em Ijuí não houve rivais no controle político, isto é, o coronel local não teve opositores: "Dico parecia ser o único 'coronel' no sentido que os estudos do mandonismo confere ao termo" (AVANCINI, s/d, p. 31). A oposição não chegava a ameaçar o poder do coronel, nem mesmo chegava a abalar-lhe o prestígio frente à comunidade.

Quando Vargas instituiu o Estado Novo, o Cel. Dico sentiu que os tempos haviam mudado. Não esperou pelo que pudesse acontecer, renunciando ao seu cargo no início de 1938. Transferiu então seu segmento de negócios para Porto Alegre, onde falece em 1955, com 81 anos de idade.

O Coronel Dico foi um típico representante dos interesses republicanos no município, sabendo responder à altura às ordens provindas do governo estadual. A relação do Coronel Dico com outros coronéis da região, principalmente com Firmino de Paula, de Cruz Alta, fora uma constante. Troca de informações, defesa de interesses pessoais e perseguição aos opositores eram práticas comuns.

Aos poucos, no entanto, o poder político do Cel. Dico começa a enfraquecer. Se está falando do ano de 1934, ano em que o país promulgou a sua nova Constituição, em 16 de julho de 1934. Marilda Silva (2003) relata os últimos momentos da vida política do Cel. Dico: 


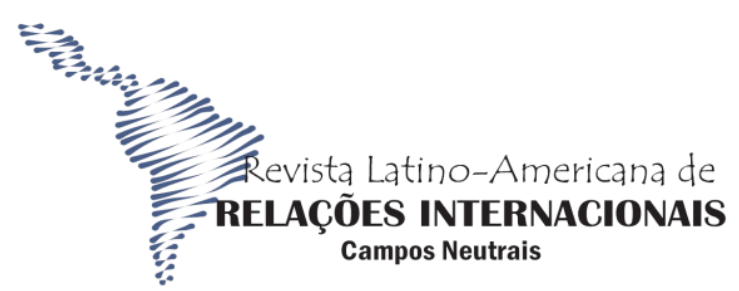

FURG

No ano seguinte, em Ijuhy, apesar da quantidade expressiva de votos contrários, o Coronel Dico ainda galgou o mandato de primeiro prefeito eleito pelo voto universal. Entretanto, o novo tempo exigia diferentes comportamentos, e o velho caudilho já não ocupava a mesma posição de outrora. No conturbado momento político que precedeu a ditadura imposta por Getúlio Vargas em 1937, Ijuhy assistiu ao ocaso do coronel. (SILVA, 2003 p. 146).

Os ventos realmente eram outros. No momento da destituição do General Flores da Cunha da condição de interventor do Estado do Rio Grande do Sul, um grupo de políticos lhe prestou solidariedade, e o Cel. Dico foi um deles:

Em 8 de janeiro de 1938, alegando problemas de saúde, Antônio Soares de Barros pediu exoneração do cargo de prefeito, numa atitude de fidelidade política a Flores da Cunha. Acompanhado de seu filho, o Coronel Dico deixou Ijuhy depois de 47 anos de trabalhos, radicando-se em Porto Alegre (SILVA, 2003, p. 146).

Por mais de 20 anos o Coronel Dico administrou com práticas autoritárias o município de Ijuí. O caráter idôneo do coronel em relação às finanças públicas, típico dos republicanos positivistas, foi, porém, maculado pelas práticas violentas que o seu governo adotou.

As eleições no município de Ijuí davam-se de maneira semelhante a outras regiões do Estado, isto é, sob forma fraudulenta e persuasiva pró-governo. A votação acontecia no prédio da Intendência e, nos distritos, nas casas dos Conselheiros da Intendência, controladas por pessoas de inteira confiança do coronel. Instalava-se uma mesa eleitoral, sendo o presidente desta, segundo comprovam as atas, pessoas de maior confiança do Cel. Dico (ACKER e SILVA, 1990). Como bem relata um convite do Cel. Dico expresso no Jornal da cidade: “Aproveito a ocasião para convidar todos os eleitores federais e estaduais para a eleição do presidente do Estado, que realizar-se-á no dia 25 de novembro e estou inteiramente convencido que todos os meus eleitores comparecerão como sempre" (CORREIO SERRANO, 25 de outubro de 1917).

Em outra passagem, o Cel. Dico expõe o pedido de votos pró-Borges de Medeiros. Em nota intitulada À Borges de Medeiros - Co-religionário e amigo, Soares de Barros assim se expressa:

Está marcado o dia 25 do corrente para a eleição de Presidente do Estado. É candidato à re-eleição o nosso chefe Exmo. Sr. Dr. A. A. Borges de Medeiros, que

\begin{tabular}{|c|c|c|c|c|} 
ISSN 2596-1314 & & & \\
CAMPOS NEUTRAIS & vio Grande & v. 3, n. 2 & p. 72-94 & Maio-Ago 2021 \\
\hline
\end{tabular}




\begin{abstract}
é uma garantia da continuação da ordem e progresso do Estado, pela sua grande competência administrativa e abnegação política. Estou certo que concorreis com vosso voto para tão merecida reeleição. Antecipo agradecimentos, sou com apreço vosso" (CORREIO SERRANO, 23 de novembro de 1917).
\end{abstract}

Certamente os pedidos de Coronel Barros foram atendidos, juntamente, é claro, dos demais coronéis subalternos ao comando de Borges de Medeiros, que venceu com 1619 votos, não tendo votos contrários (CORREIO SERRANO, 26 de novembro de 1917).

$\mathrm{O}$ aliciamento dos eleitores e a propaganda republicana eram uma constante em Ijuí. As eleições para presidente e vice-presidente da República, deputados federais e senador, marcadas para o dia $1^{\circ}$ de março de 1918 , foram apenas mais um exemplo. A propaganda pró-Partido Republicano era feita às claras, sem dar oportunidade a nenhum partido oposicionista. Especificamente nessa eleição, a propaganda foi dirigida ao Dr. Augusto Pestana, que, em outros tempos, fora um dos principais líderes políticos da Colônia:

\begin{abstract}
Estamos certos que nenhum companheiro deixará de cumprir com seu dever cívico, ainda mais, que é candidato o nosso sempre lembrado e querido amigo Dr. Augusto Pestana, que tantos serviços prestou a esta terra e no Congresso, ao nosso querido Estado ocasião oportuna de mostrarmos a nossa gratidão para aquele que sempre procurou o progresso e o engrandecimento de Ijuí (CORREIO SERRANO, 28 de janeiro de 1918).
\end{abstract}

No final, o pedido lembra que o comparecimento de todos, votando no candidato republicano, será do agrado e satisfação do chefe maior do município, o Cel. Soares de Barros. O jornal Correio Serrano também tece comentários saudando ao "Deputado e candidato à re-eleição Augusto Pestana" por ocasião de sua visita em campanha eleitoral à cidade de Ijuí:

\begin{abstract}
Nos últimos quatro anos, como deputado federal, ele trabalhou eficazmente na Câmara Federal a favor de nosso Estado e especialmente de nossa região. Sem dúvida, a sua reeleição no dia $1^{\circ}$ de março é certa; o partido republicano não pode apresentar um nome mais satisfatório como o seu e o eleitorado renderá suas graças unanimemente neste dia. Ao ilustríssimo hóspede nossas sinceras saudações (CORREIO SERRANO, 15 de fevereiro de 1918).
\end{abstract}

Quanto ao resultado da referida eleição, o mesmo seguiu dentro do esperado, ou seja, a vitória expressiva dos candidatos republicanos. (CORREIO SERRANO, 4 de março de 1918).

O Cel. Soares de Barros cumpriu com fidelidade e êxito irrestrito as determinações do seu chefe maior, o republicano Borges de Medeiros, durante o longo período em que se colocou à frente da administração do município de Ijuí, como fica expresso na conclamação exposta a seguir: "O nosso chefe Exmo. Sr. Dr. Borges de Medeiros recomenda nomes de companheiros conhecidos de serviço ao Estado para serem eleitos pelo nosso Partido" (CORREIO SERRANO, 11 de fevereiro de 1918). 


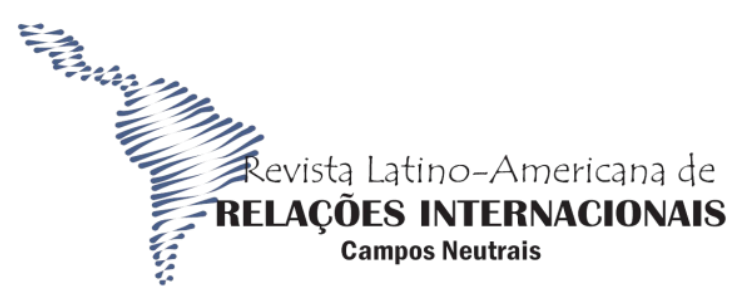

Depois da expressiva vitória dos republicanos nas eleições de 1918, Borges de Medeiros agradeceu ao esforço do Cel. Barros no sucesso do empreendimento. Borges assim se expressou nota assinada no jornal da cidade:

Tendo esse município contribuído notavelmente para a extraordinária vitória republicana de $1^{\circ}$ de março, apraz-me reconhecer e louvar a porfiada ação que desenvolvestes, não só durante a fase preparatória do alistamento, como depois em todos os termos do processo eleitoral. Aceite por isso minhas congratulações cívicas com votos sinceros pela consolidação crescente de vosso merecido prestígio (CORREIO SERRANO, 15 de março de 1918).

Da mesma forma, o proselitismo e os pedidos de votos do Cel. Dico continuaram, nas eleições seguintes, sempre instigando e direcionando o eleitorado a votar nos candidatos republicanos. Como aconteceu quando o candidato Epitácio Pessoa fora indicado pelo Partido Republicano para concorrer à Presidência da República em 1919: "Pleiteando ou não a eleição, cumpramos com o nosso dever concorrendo às urnas e votando no Dr. Epitácio Pessoa. Espero o concurso de todos os amigos para que a eleição no dia 13 tenha o brilho de sempre no município" (CORREIO SERRANO, 7 de abril de 1919). O resultado foi novamente favorável ao candidato republicano. Os eleitores de Ijuí foram quase unânimes depositando seus votos à Epitácio Pessoa, que obteve 940 votos contra apenas 9 votos atribuídos a Rui Barbosa.

O apoio incondicional do Cel. Soares de Barros, assim como de outros coronéis, a Borges de Medeiros lhes possibilitava, em contrapartida, garantir a sua permanência no poder local. Os favorecimentos de Barros a Borges e vice-versa acabaram consolidando uma aliança que garantiu mandatos de longa duração para ambos. Se Barros pedia votos para Borges, este fazia o mesmo, como explicita o comentário do Correio Serrano da época:

O Dr. Borges de Medeiros, tendo em vista os elevados serviço prestados pelo Sr. Coronel Antônio Soares de Barros, enviou um telegrama ao presidente do Conselho Municipal manifestando a sua solidariedade à reeleição do mesmo, que jamais podemos recuar, sabendo-se que o município está nas mãos de um administrador modelo. (CORREIO SERRANO, 4 de janeiro de 1921).

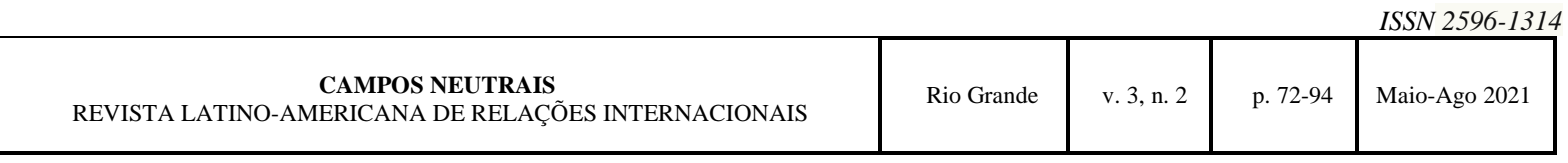


No mês de fevereiro de 1921 ocorreram as eleições para preenchimento de vagas para senadores e deputados federais. Nelas os republicanos receberam 1630 votos (CORREIO SERRANO, 23 de fevereiro de 1921).

Somente em 1924 começa a aparecer em Ijuí, embora de maneira tímida e reduzida, um quadro político de oposicionistas. Estava à frente o Sr. Ângelo Strapazon, que formou uma junta provisória pró-Assis Brasil, líder político do Partido Federalista e opositor de Borges de Medeiros. No Estado, formou-se a Aliança Libertadora, tendo como presidente honorário o Dr. Joaquim Francisco de Assis Brasil e Júlio César Ilgenfritz, como presidente efetivo. Da mesma forma, em Ijuí, formou-se a Aliança, tendo a direção de Eduardo Knebel e Ângelo Strapazon. Os oposicionistas, com isso, conseguem, aos poucos, ameaçar a hegemonia republicana em Ijuí. Nas eleições para o Senado e Câmara, transcorridas no dia 7 de maio de 1924, os republicanos fizeram 1.156 votos contra 325 dos oposicionistas.

Em 1925, as eleições eram para escolher um novo intendente e para o preenchimento de vagas de representantes à Assembléia Legislativa. Nestas eleições, o Cel. Soares de Barros fora proibido de concorrer em decorrência do Tratado de Pedras Altas; no entanto, a influência do coronel na política ijuiense permanece inalterada. Soares de Barros indicou o Cel. Alfredo Steglich para estar à frente da Intendência Municipal, que vence com facilidade o pleito do dia 15 de março de 1925, com 1597 votos (CORREIO SERRANO, 18 de março de 1925).

Um ano depois (1926) estava marcada, para o dia $1^{\circ}$ de março, a eleição para presidente e vice-presidente da República. Novamente o Cel. Soares de Barros indica a seus cativos eleitores o nome do Dr. Washington Luiz, para que fosse eleito. As eleições, conforme o relato do jornal Correio Serrano, ocorreram sem muita animação; mesmo assim, os candidatos indicados por Soares de Barros venceram em Ijuí, totalizando 1.320 votos em todo o município.

Quando da ausência do Cel. Soares de Barros à frente da direção política do município, cessaram as notícias sobre a política no município. São raras as vezes em que o nome do Cel. Steglich é mencionado, a não ser quando ele vem a renunciar. Então, o jornal da cidade pede a volta do Cel. Soares de Barros à direção do município:

Por esse motivo, o Correio Serrano não pode deixar de associar-se às justas e merecidas manifestações de veneração e apreço que no íntimo de todos os ijuienses serão prestados ao coronel Antônio Soares de Barros, e damos expressão à esperança de vê-lo novamente voltar à direção dos interesses públicos a bem dos seus co-munícipes reconhecidos (CORREIO SERRANO, 2 de abril de 1926). 


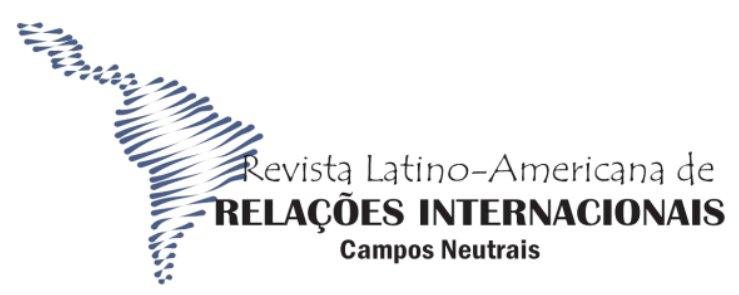

Em 25 de novembro de 1927 aconteceu a eleição para presidente do Estado. Soares de Barros, mesmo não estando à frente da direção política, faz campanha para Getúlio Vargas que sai vencedor do pleito e, em Ijuí, o Partido Republicano recebe 2.394 votos. Vargas ascendeu sob forma meteórica na política: enquanto presidente do Estado, construiu alianças, inclusive com o Partido Libertador - que fora seu opositor anteriormente, unificou as oposições e formou a "Frente Única”, credenciando-se a postular o cargo maior do Brasil, o de presidente da República. Vargas, mesmo sendo derrotado por Júlio Prestes e Vital Soares, depois de uma eleição fraudulenta de parte a parte, deflagrou a Revolução 22 dias antes do término do governo de Washington Luís. Com a Revolução de 30, Flores da Cunha foi nomeado interventor provisório da República no Estado do Rio Grande do Sul.

O intendente Cel. Steglich renunciou em janeiro de 1928. Assumiu, em março do mesmo ano, o Dr. Kuhlmann, que administrou o município até 13 de fevereiro de 1929, quando foi substituído pelo Cel. Soares de Barros, que voltou à frente da direção política municipal sendo eleito pelos cidadãos ijuienses com 2.742 votos.

O Cel. Soares de Barros volta ao controle político do município e passa a apoiar o Partido Liberal pró-Vargas e depois o Partido Republicano Liberal (PRL).

Em outubro de 1934 ocorreram eleições gerais a deputados constituintes. Em Ijuí compareceram às urnas 2.940 eleitores, com uma abstenção de $24 \%$. A maioria dos votos foi para o Partido Republicano Liberal, que fez 1.627 votos para a Câmara dos Deputados, seguidos pela Frente Única Gaúcha (FUG), formada pelo Partido Republicano RioGrandense e Partido Libertador, que obteve 1.129 e pela Ação Integralista Brasileira (AIB), com 12 votos (CORREIO SERRANO, 10 de novembro de 1934).

Em fins de 1934 houve eleições municipais em Ijuí e, pela primeira vez, o Cel. Dico levava um número expressivo de votos contrários. Acontecia que os colonos estavam descontentes com o preço pago pela banha, pelos comerciantes. Os colonos aproveitaram a primeira vez que o voto era secreto e votaram contra o coronel Dico.

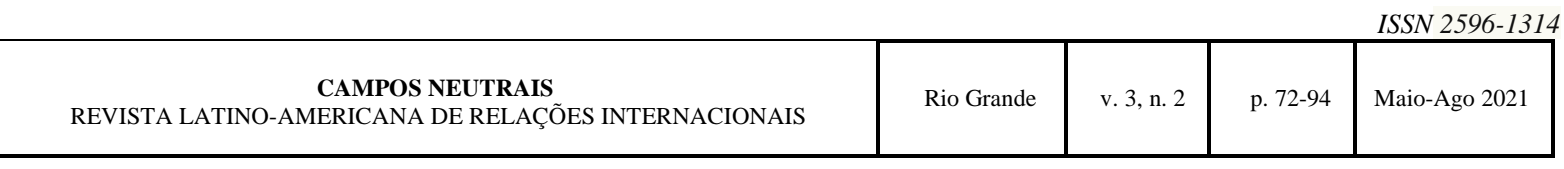


Em meados dos anos 1930 o poder político dos coronéis entra num processo de esgotamento e de insustentabilidade. Nesse ínterim, chega ao fim o ciclo político do poderoso coronel Dico, que renunciou ao posto de chefe maior depois de longos anos à frente do controle político no município.

\section{Considerações finais}

Durante a República Velha (1890-1930), o mecanismo privilegiado de acesso e permanência no poder político brasileiro e gaúcho foi o coronelismo, cuja característica define a correlação de forças históricas, bem como, implica a configuração do sistema político brasileiro. É bem verdade que o coronelismo tenha sido um evento histórico datado e limitado, no entanto, é possível inferir sua contribuição para a formação e consolidação de uma cultura política nacional marcadamente subserviente.

Fica claro na exposição do caso do coronel Dico, quão contraditória era a relação coronelista que implicava na manutenção da ordem e proteção dos 'bons' cidadãos e, de outro lado, na inviabilidade de oposição e a violência com que se tratava os indivíduos de comportamento socialmente não aceito. Ao mesmo tempo em que a relação clientelista permitia a manutenção eleitoral no poder, as relações patrimonialistas e patriarcais possibilitavam a premiação da fidelidade. Essas três características, é preciso observar, necessariamente se retroalimentam e mantém.

A cultura política brasileira forjada com base nessas características carrega muito das relações de subordinação e apego ao 'salvador da pátria', líder político austero e generoso capaz de trazer a solução dos problemas, principalmente a manutenção da ordem e a prosperidade, objetivos claramente positivistas (CARVALHO, 2007).

Uma parte da ciência política brasileira relativiza excessivamente a importância das categorias de coronelismo, clientelismo e patrimonialismo, para explicar a relação entre sociedade e Estado (SOUZA, 2003). Não obstante, o estudo ora em tela vai no caminho contrário e, talvez, se outros autores se aventurarem a fazer estudos de caso análogos, poderemos nos surpreender com a importância interpretativa dessas categorias para o sistema político brasileiro contemporâneo. 


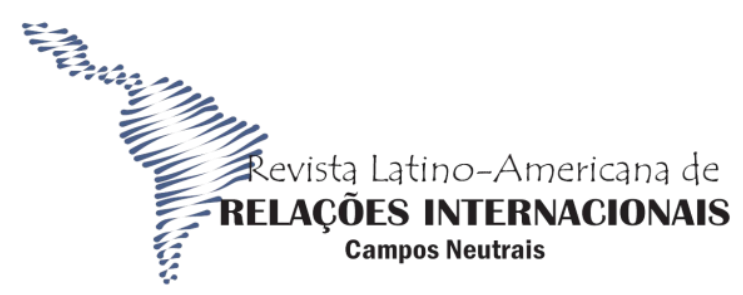

\section{Referências}

ACKER, Celso; SILVA, Maria Almeida da Silva. Cadernos do Centenário. Jornal da Manhã. Ijuí: 30 de junho de 1990.

AGOSTINI, João. MADP: Ijuí, 12 de outubro de 1987. Entrevista concedida a Danilo Lazzarotto.

ÁLBUM COMEMORATIVO DO CINQÜENTENÁRIO DA FUNDAÇÃO DE IJUÍ. Ijuí: Litografia Serrana, 1940.

AMARAL, Sandra Maria do. Elite política e relações de poder: o caso de Ijuí (19381945). Ijuí: Unijuí, 2003.

AVANCINI, Elsa Gonçalves. Coronelismo, cooptação e resistência: 1200 votos contra o coronel - a eleição da banha em Ijuí, 1934. Porto Alegre: Secretaria do Estado da Educação, Projeto Melhoria da Qualidade de Ensino, 1993.

AVANCINI, Elsa Gonçalves. O mandonismo local em Ijuí: 1912-1937. Ijuí: texto datilografado, s/d, MADP/Unijuí.

ÁVILA, Luis Carlos. Guia biográfico das ruas de Ijuí. Ijuí: MADP/Unijuí, 1982.

BAQUERO, Marcello; PRÁ, Jussara Reis. Matriz histórico-estrutural da cultura política no RS e padrões de participação política. Porto Alegre: Cadernos de Ciência Política n. 3, UFRGS, 1995.

BARBIAN, Hilário. Levantamento de fontes sobre a história do coronelismo em Ijuí. Ijuí: MADP/Unijuí, 1986 (Apostila).

CARVALHO, José Murilo de. "Mandonismo, coronelismo, clientelismo: uma discussão conceitual”. In: Dados, vol. 40, 2, Rio de Janeiro, 1997.

CARVALHO, José Murilo de. Cidadania no Brasil: o longo caminho. $9^{\text {a }}$ Ed. Rio de Janeiro:

Civilização Brasileira, 2007.

CAVALARI, Rossano Vieiro. O ninho dos pica-paus: Cruz Alta na Revolução Federalista de 1893. Porto Alegre, RS: Martins Livreiro, 2001.

COSTA, Alfredo R. da. O Rio Grande do Sul: completo estudo sobre o Estado. 2. ed. Porto Alegre, RS: Livraria do Globo, 1922.

\begin{tabular}{|l|l|l|l|l|}
\hline $\begin{array}{l}\text { ISSN 2596-1314 } \\
\text { CAMPOS NEUTRAIS }\end{array}$ & Rio Grande & v. 3, n. 2 & p. 72-94 & Maio-Ago 2021 \\
\hline
\end{tabular}


ENCICLOPÉDIA RIO-GRANDENSE. Canoas: Editora Regional, 1958, vol. 5, p. $287-$ 288.

FÉLIX, Leiva Otero. Coronelismo, borgismo e cooptação política. Porto Alegre, RS: Mercado Aberto, 1987.

FISCHER, Martin. Augusto Pestana: o homem e sua obra. Ijuí: MADP/Unijuí, 1968.

FLORES, Moacyr; FLORES, Hilda Agnes Hübner. Rio Grande do Sul: aspectos da Revolução de 1893. Porto Alegre, RS: Martins, 1993.

FREITAS, Décio. O homem que inventou a ditadura no Brasil. 5. ed. Porto Alegre, RS: Sulina, 2000.

IJUÍ. RELATÓRIO MUNICIPAL DE 1923. Ijuí: MADP/Unijuí.

JORNAL CORREIO SERRANO, edição de 2 de abril de 1926.

JORNAL CORREIO SERRANO, edição de 4 de janeiro de 1921.

JORNAL CORREIO SERRANO, edição de 4 de março de 1918.

JORNAL CORREIO SERRANO, edição de 7 de abril de 1919.

JORNAL CORREIO SERRANO, edição de 9 de dezembro de 1934.

JORNAL CORREIO SERRANO, edição de 11 de fevereiro de 1918.

JORNAL CORREIO SERRANO, edição de 11 de janeiro de 1933.

JORNAL CORREIO SERRANO, edição de 15 de fevereiro de 1918.

JORNAL CORREIO SERRANO, edição de 15 de março de 1918.

JORNAL CORREIO SERRANO, edição de 18 de março de 1925.

JORNAL CORREIO SERRANO, edição de 18 de outubro de 1922.

JORNAL CORREIO SERRANO, edição de 20 de dezembro de 1922.

JORNAL CORREIO SERRANO, edição de 23 de fevereiro de 1921.

JORNAL CORREIO SERRANO, edição de 23 de novembro de 1917.

JORNAL CORREIO SERRANO, edição de 25 de outubro de 1917.

JORNAL CORREIO SERRANO, edição de 26 de novembro de 1917.

JORNAL CORREIO SERRANO, edição de 27 de setembro de 1944. 


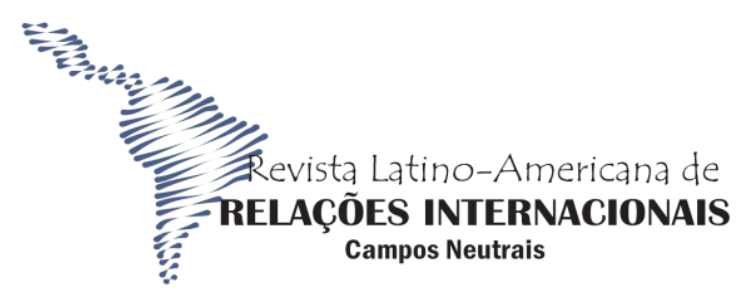

JORNAL CORREIO SERRANO, edição de 28 de janeiro de 1918.

JORNAL CORREIO SERRANO, edição de 30 de maio de 1934.

JORNAL CORREIO SERRANO, edição de 4 de maio de 1933.

JORNAL CORREIO SERRANO, edição de 6 de setembro de 1933.

LAZZAROTTO, Danilo. Alto da União e sua história. Ijuí: Unijuí, 1986.

LAZZAROTTO, Danilo. Os capangas do coronel: romance histórico. Ijuí: Unijuí, 1995.

LEAL, Vitor Nunes. O coronelismo, enxada e voto: o município e o regime representativo no Brasil. São Paulo: Alfa-Ômega, 1975.

LOVE, Joseph L. O regionalismo gaúcho. São Paulo: Perspectiva, 1975.

NUNES, Edson. A gramática política do Brasil: clientelismo e insulamento burocrático. Rio de Janeiro: Jorge Zahar Editor, 2003.

MADP. Livro de Estudos Sociais. Ijuí: UNIJUÍ / Museu Antropológico Diretor Pestana, s/d.

PICCOLO, Helga I. L. “A política rio-grandense no Império". In: DACANAL, José Hildebrando; GONZAGA, Sergius (Org.). RS: Economia e política. Porto Alegre, RS: Mercado Aberto, 1979.

PINTO, Céli R. J. Castilhos e suas circunstâncias. In: ZERO HORA, 25 de outubro de 2003, p. 4.

PINTO, Céli R. J. Positivismo: um projeto político alternativo (RS 1889-1930). Porto Alegre, RS: LPM, 1986.

RIO GRANDE DO SUL EM REVISTA. Porto Alegre, RS: Globo, 1930.

SILVA, Marilda Almeida da. Fragmentos: vestígios que contam histórias Ijuhy (18901942). Porto Alegre: Programa de Pós-Graduação em Artes Visuais da UFRGS, 2003 (Dissertação de Mestrado).

SOUZA, Celina. "Estado do campo" da pesquisa em políticas públicas no Brasil. RBCS, vol. 18, No 51, 2003. 
TRINDADE, Hélgio Henrique Casses. "Aspectos do sistema partidário republicano riograndense (1882-1937)”. In: DACANAL, José Hildebrando; GONZAGA, Sergius (Orgs.). RS: economia e política. Porto Alegre, RS: Mercado Aberto, 1979.

TRINDADE, Hélgio; NOLL, Maria Izabel. Subsídios para a história parlamentar gaúcha: 1890-1937. Porto Alegre, RS: CORAG, 2005.

VÉLEZ, Ricardo. O castilhismo: curso de introdução ao pensamento político brasileiro. Brasília, DF: Universidade de Brasília, 1982.

VÉLEZ, Ricardo. Castilhismo: uma filosofia da República. Porto Alegre, RS: EST; Caxias do Sul: Universidade de Caxias do Sul, 1980.

XAVIER, Odila Barros. 60 anos dentro de uma firma: 1890-1950. Porto Alegre, RS: Globo, 1951. 